UDC $519.6: 519.81$

DOI: $10.20535 /$ SRIT.2308-8893.2021.1.12

\title{
QUINTILE REGRESSION BASED APPROACH FOR DYNAMICAL VAR AND CVAR FORECASTING USING METALOG DISTRIBUTION
}

\author{
G. ZRAZHEVSKY, V. ZRAZHEVSKA
}

\begin{abstract}
The paper proposes a new method of dynamic VaR and CVaR (ES) risk measures forecasting. Quantile linear GARCH model is chosen as the main forecasting model for time series quantiles. To build a forecast, the values of quantiles are approximated by the metalog distribution, which makes it possible to use analytical formulas to evaluate risk measures. The method of $\mathrm{VaR}$ and $\mathrm{CVaR}$ forecasting is formulated as a step-by-step algorithm. At the first stage, an initial model is built to obtain variance estimates. The predicted variance values obtained from the constructed model are used at the second stage to find the QLGARCH model coefficients by solving the minimization problem. At the third stage, the QLGARCH models are estimated on a non uniform quantile grid. The obtained predicted values of quantiles are used to estimate the approximating metalog distribution. The investigated theory is applied to $\mathrm{VaR}$ and $\mathrm{CVaR}$ forecasting for time series of daily log return of the DJI index.
\end{abstract}

Keywords: VaR, CVaR, Expected Shortfall, dynamic risk measures, forecast, Quantile LGARCH model, metalog distribution.

\section{INTRODUCTION}

The purpose of this study is to develop the new method of dynamic VaR and $\mathrm{CVaR}$ risk measures estimation and forecasting. $\mathrm{VaR}$ and $\mathrm{CVaR}$ are classic measures that are used in financial risk assessment [1]. In the practice of VaR and $\mathrm{CVaR}$ estimating for a random variable that describes the profitability of a financial instrument, two main approaches can be distinguished. The first approach is a nonparametric estimation method that is based on an empirical distribution function. The disadvantage of this estimation method is the critical dependence of the effectiveness of the method on the presence in the initial data of values that arise with low probabilities [1]. The second approach is parametric, based on a priori estimation of the distribution function, which is the main disadvantage of this approach [1].

In time series analysis, in particular, in time series forecasting, in addition to static risks measures, in practice it becomes necessary to build more complex risk models, which take into account the changes of the series over time. In this case, to estimate risk measures, various time series models can be used, such as, for example, ARMA, GARCH. With this approach, the problem of risk measures modeling is reduced to the estimation of a model for variance and finding static risk measures for its residuals using parametric or nonparametric methods. Examples of this approach are described in [2-4].

The described above approaches of evaluation of risk measures are based on the construction of a cumulative distribution function on the full space of events. 
At the same time, to estimate risk measures, it is sufficient to evaluate only the quantile of a given level (for VaR) or the distribution of values exceeding a given level (for $\mathrm{CVaR}$ ). At the same time, from a practical point of view, the most significant is the distribution for a relatively small subset of the event space leading to extreme consequences. Accordingly, it is possible to simplify the forecasting task by using the quantile regression model proposed in $[5,6]$ contains a detailed description of the theory of quantile regression estimation applicable to standard time series models. Since financial time series, as a rule, are characterized by rather strong volatility, quantile GARCH models are popular for risk analysis. The problem of building quantile models of the GARCH class and their application in VaR forecasting for the series of log returns of stock market indices is considered, for example, in $[7,8]$.

One of the possible approaches for fitting of the GARCH model residuals distribution is to use the metalog distribution proposed in [9]. This choice is based on the simplicity of quantile formulas and the availability of a sufficient set of parameters of this distribution for an adequate fitting of empirical data of various nature. Thus, in [10], the metalog distribution is used in the development of the extended FAIR-BN combined approach for cyber security risk assessment. In [11], the five-term metalog distribution is used to forecast fertility rates in Canada. SPT (symmetric-percentile triplet) metalog distribution is used in [12] to statistically compare the forecasts of annual production in the oil and gas industry in Norway. In [13], the metalog distribution is used for dynamic risk measures VaR and CVaR estimating based on a heteroscedastic time series model, taking into account the strong dependence of the data series. The method of smoothing of the autocorrelation function is used for variance modeling. A metalog distribution is proposed to use for risk measures model residuals estimating. The paper proposes two methods of metalog distribution estimating and explicit analytical formulas for $\mathrm{VaR}$ and $\mathrm{CVaR}$ modeling and forecasting with different numbers of members in the metalog distribution.

A large number of publications devoted to the risk measures estimation and forecasting testifies to the applied significance of this problem. At the same time, the task of developing the new methods and approaches for risk modeling, which more fully reflect the nature of the modeled series, remains relevant. Most of the forecasting methods are based on the estimation of the entire distribution function. On the one hand, this is an overstated requirement for the model, and on the other hand, it often leads to an incorrect description of tails of distribution. Therefore, in this paper, it is proposed to build volatile models only for the tail parts of the distribution. In this case, the obtained point values of the quantiles can be smoothed, for example, by metalog distribution.

\section{MATERIALS AND METHODS}

On the probability space $\left(\Omega, \Phi_{t}, P\right)$ a time series $\left\{u_{t}, t \in T\right\}$ with a finite mean is considered $\left(\Phi_{t}\right.$ is the information set containing all available at the time $\mathrm{t}$ information about the time series).

For a fixed confidence level $\alpha$ risk measure $V a R_{\alpha}^{t}$ is defined as the conditional $\alpha$ - quantile of the $\operatorname{CDF}$ of $u_{t}: \operatorname{VaR}_{\alpha}^{t}=F_{t}^{-1}(\alpha)$. The risk measure 
$C V a R_{\alpha}^{t}$ is defined as the integral: $C V a R_{\alpha}^{t}=E_{t}\left[u_{\widetilde{t}} \mid u_{\tilde{t}}<-V a R_{\alpha}^{t}\right]=-\frac{1}{\alpha} \int_{0}^{\alpha} \operatorname{VaR} R_{\gamma}^{t} d \gamma$, $(\alpha<0.5)$, where $E_{t}[\cdot]$ denotes expectation with respect to $\Phi_{t}$. In this paper, the continuity of the $\mathrm{CDF}$ is assumed.

As indicated in the introduction, most methods for dynamic VaR and CVaR risk measures forecasting are based on time series modeling. The GARCH models are among the models that describe volatility of financial time series. In this paper, we consider the Linear GARCH model LGARCH $(p, q)$. This model is frequently used for fitting log return volatility time series and appropriate for quantile regression because of its linear structure [7].

The time series $\left\{u_{t}, t=0,1,2, \ldots\right\}$ follows $\operatorname{LGARCH}(p, q)$ process if:

$$
u_{t}=\sigma_{t} \varepsilon_{t}, \quad \sigma_{t}=\beta_{0}+\sum_{i=1}^{q} \gamma_{i}\left|u_{t-i}\right|+\sum_{j=1}^{p} \beta_{j} \sigma_{t-j},
$$

where $\left\{\varepsilon_{t}\right\}$ are independent, identically distributed random variables with zero mean and a conditional distribution function $F_{\varepsilon}(\cdot), \beta_{0}>0 ;\left(\gamma_{1}, \gamma_{2}, \ldots, \gamma_{q}\right)^{\mathrm{T}} \in R_{+}^{q}$.

Using the heteroscedastic time series model, the dynamic risk measures can be found under the following formulas [1]:

$$
\operatorname{VaR}_{\alpha}^{t}=\operatorname{VaR}_{\alpha}(\varepsilon) \sigma_{t}, C V a R_{\alpha}^{t}=C V a R_{\alpha}(\varepsilon) \sigma_{t},
$$

where the model for $\sigma_{t}$ is defined in $(1), \operatorname{VaR}_{\alpha}(\varepsilon)$ and $\operatorname{CVaR}_{\alpha}(\varepsilon)$ are static risk measures at time $t$. Then the $P$ step forecast for dynamic risk measures can be found by model (2) extrapolation:

$$
\operatorname{VaR}_{\alpha}^{t+P}=\operatorname{VaR}_{\alpha}(\varepsilon) \sigma_{t+P}, C V a R_{\alpha}^{t+P}=C V a R_{\alpha}(\varepsilon) \sigma_{t+P} .
$$

In this work, the following methods are used to evaluate static risk measures $\operatorname{VaR}_{\alpha}(\varepsilon), \operatorname{CVaR}_{\alpha}(\varepsilon)$.

Historical simulation method. Let $X$ be a random variable and its sample values are $X_{1}, X_{2}, \ldots, X_{N}$. In accordance with the historical simulation method, an empirical distribution function is constructed on the sample values. Then according to [14]:

$$
\operatorname{VaR}_{\alpha}=-X_{([N \alpha])}, C V a R_{\alpha}=-\left(\sum_{i=1}^{[N \alpha]} X_{(i)}\right) /([N \alpha]),
$$

where $X_{(1)} \leq X_{(2)} \leq \ldots \leq X_{(N)}$.

Using Student's $\boldsymbol{t}$-distribution. If the random variable has the local scale Student's $t$-distribution with the parameters $\mu, \sigma$ and the degrees of freedom $v>2$, then the risk measures can be calculated as (see [14]):

$$
\operatorname{VaR}_{\alpha}=\mu+\sigma t_{\mathrm{v}}^{-1}(\alpha), C V a R_{\alpha}=\mu-\sigma \frac{g_{\mathrm{v}}\left(t_{\mathrm{v}}^{-1}(\alpha)\right)}{\alpha} \cdot \frac{\mathrm{v}+\left(t_{\mathrm{v}}^{-1}(\alpha)\right)^{2}}{v-1},
$$

where $g_{\mathrm{v}}(\cdot)$ is the standard PDF and $t_{\mathrm{v}}{ }^{-1}(\cdot)$ is the inverse standard CDF value at $\alpha$ of $t$-distribution. 
Using metalog distribution. Suppose that $X$ has a metalog distribution $F_{X}(x)$, that is defined by a quantile function $M_{n}(\alpha, a(X, \alpha))[9]$ :

$$
M_{n}(\alpha, \boldsymbol{a})= \begin{cases}a_{1}+a_{2} \ln \frac{\alpha}{1+\alpha}, & n=2 ; \\ a_{1}+a_{2} \ln \frac{\alpha}{1+\alpha}+a_{3}(\alpha-0,5) \ln \frac{\alpha}{1+\alpha}, & n=3 ; \\ a_{1}+a_{2} \ln \frac{\alpha}{1+\alpha}+a_{3}(\alpha-0,5) \ln \frac{\alpha}{1+\alpha}+a_{4}(\alpha-05), & n=4 ; \\ M_{n-1}+a_{n}(\alpha-0,5)^{\frac{n-1}{2}}, & \text { for odd } n \geq 5 ; \\ M_{n-1}+a_{n}(\alpha-0,5)^{\frac{n}{2}-1} \ln \frac{\alpha}{1+\alpha}, & \text { for even } n \geq 5 .\end{cases}
$$

The coefficients $\boldsymbol{a}=\left(a_{1}, a_{2}, \ldots, a_{n}\right)^{\mathrm{T}}$ can be found as a solution of the system of equations:

$$
\boldsymbol{a}=\left[\boldsymbol{Y}_{\boldsymbol{n}}^{\mathrm{T}} \boldsymbol{Y}_{n}\right]^{-1} \boldsymbol{Y}_{\boldsymbol{n}}^{\mathrm{T}} \boldsymbol{X},
$$

where $\boldsymbol{X}=\left(X_{1}, X_{2}, \ldots, X_{N}\right)^{\mathrm{T}}$, the matrix $\boldsymbol{Y}_{n}$ is defined through a set of quantiles with levels $\boldsymbol{\alpha}=\left(\alpha_{1}, \alpha_{2}, \ldots, \alpha_{N}\right)^{\mathrm{T}}=\left(F_{X}\left(X_{1}\right), F_{X}\left(X_{2}\right), \ldots, F_{X}\left(X_{N}\right)\right)^{\mathrm{T}}$ [9].

Following the definitions, risk measures can be found under the formulas:

$$
\begin{gathered}
\operatorname{VaR}_{\widetilde{\alpha}}(X)=-M_{n}(\widetilde{\alpha}, \boldsymbol{a}(X)) ; \\
\operatorname{CVaR}_{\widetilde{\alpha}, n}(X)=-\frac{1}{\widetilde{\alpha}} \int_{0}^{\widetilde{\alpha}} M_{n}(y, \boldsymbol{a}(X)) d y .
\end{gathered}
$$

Explicit formulas for $\operatorname{CVaR}_{\widetilde{\alpha}, n}(X)$ estimating with different number of members of the metalog distribution were obtained in [13]:

$$
= \begin{cases}\operatorname{CVaR}_{1}+a_{2}\left(\frac{\ln (1-\widetilde{\alpha})}{\widetilde{\alpha}}+\ln \frac{\widetilde{\alpha}}{1-\widetilde{\alpha}}\right), & n=2 ; \\ \operatorname{VVaR}_{\widetilde{\alpha}, 2}(X)+\frac{a_{3}}{2}\left(1+(\widetilde{\alpha}-1) \ln \frac{\widetilde{\alpha}}{1-\widetilde{\alpha}}\right), & n=3 ; \\ \operatorname{VVaR}_{\widetilde{\alpha}, 3}(X)+\frac{a_{4}(\widetilde{\alpha}-1)}{2}, & n=4 ; \\ \operatorname{VVaR}_{\widetilde{\alpha}, n-1}(X)+\frac{2 a_{n}}{\widetilde{\alpha}(1+n)}\left((-1)^{\frac{n-1}{2}}(0,5)^{\frac{n+1}{2}}+(\widetilde{\alpha}-0.5)^{\frac{n+1}{2}}\right), & \text { for odd } n \geq 5 ; \\ \operatorname{VVaR}_{\widetilde{\alpha}, n-1}(X)+\frac{2^{\frac{2-n}{2}} a_{n}}{n \widetilde{\alpha}} 2(2 \widetilde{\alpha}-1)^{\frac{n}{2}} \operatorname{arctg}(2 \widetilde{\alpha}-1)+n G+ & \\ +\ln (1-\widetilde{\alpha})+(-1)^{\frac{n+2}{2}} \ln \widetilde{\alpha}, & \text { for even } n \geq 6 .\end{cases}
$$

where 


$$
\begin{gathered}
G={ }_{3} F_{2}[1,1,1-n / 2 ; 2,2 ; 2]+(\widetilde{\alpha}-1)_{3} F_{2}[1,1,1-n / 2 ; 2,2 ; 2-2 \widetilde{\alpha}]+ \\
+(-1)^{n / 2} \widetilde{\alpha}_{3} F_{2}[1,1,1-n / 2 ; 2,2 ; 2 \widetilde{\alpha}]
\end{gathered}
$$

${ }_{3} F_{2}\left[c_{1}, c_{2}, c_{3} ; d_{1}, d_{2} ; z\right]$ is generalized hypergeometric function.

For determining the parameters of the metalog distribution the Quantile Metalog Method is proposed in [13]. This method uses the approximation of the empirical distribution function by sample quantiles $\boldsymbol{X}=\left(\tau_{\alpha_{1}}, \ldots, \tau_{\alpha_{N}}\right)^{\mathrm{T}}$, where

$$
\begin{aligned}
& \tau_{\alpha_{i}}= \begin{cases}X_{\left(\left[n \alpha_{i}\right]+1\right)}, & \text { if } n \alpha_{i} \text { is not integer; } \\
\frac{\bar{\alpha}-\alpha_{i}}{\bar{\alpha}-\alpha} X_{(\alpha)}+\frac{\alpha_{i}-\alpha}{\bar{\alpha}-\alpha} X_{-} X_{(\bar{\alpha})}, & \text { if } n \alpha_{i} \text { is integer; }\end{cases} \\
& \underset{-}{\alpha}=\frac{\left[n \alpha_{i}\right]}{n}, \bar{\alpha}=\frac{\left[n \alpha_{i}+1\right]}{n}, \alpha_{i} \in(0,1) .
\end{aligned}
$$

Thus, the classical approach to risk measures forecasting (3) involves building a model for variance estimating, obtaining model residuals, and using methods for static risk measures $\operatorname{VaR}_{\alpha}(\varepsilon), \mathrm{CVaR}_{\alpha}(\varepsilon)$ estimating.

Another approach is based on estimating of quantile time series models, which makes it possible to directly simulate the time series quantile of a given level. In this paper, in accordance with (1), the QLGARCH model is considered (see [6-8]):

$$
Q_{u_{t}}\left(\tau \mid \Phi_{t-1}\right)=\theta_{t}(\tau)^{\mathrm{T}} \boldsymbol{z}_{t},
$$

where $Q_{u_{t}}\left(\tau \mid \Phi_{t-1}\right)$ is a conditional $\tau-$ quantile for $\{u\}, \quad z_{t}=$ $=\left(1, \sigma_{t-1}, \ldots, \sigma_{t-p},\left|u_{t-1}\right|, \ldots,\left|u_{t-q}\right|\right)^{\mathrm{T}}, \theta_{t}(\tau)^{\mathrm{T}}=\left(\beta_{0}, \beta_{1}, \ldots, \beta_{p}, \gamma_{1}, \ldots, \gamma_{q}\right) F^{-1}(\tau)=\left(\beta_{0}(\tau)\right.$, $\left.\beta_{1}(\tau), \ldots, \beta_{p}(\tau), \gamma_{1}(\tau), \ldots, \gamma_{q}(\tau)\right)$.

The paper proposes the following methodology for dynamic VaR and CVaR forecasting. Model (9) is used to construct a set of quantiles. For a more detailed description of the left tail of the CDF, the quantile levels can be found on a non uniform grid. Assuming that the obtained set of quantiles can be fitted by the metalog distribution, the quantile function $M_{n}(\alpha, \boldsymbol{a}(X, \alpha))$ is estimated using (6). To obtain forecasts of risk measures, formulas (7), (8) are used. The practical implementation of the method is formulated as a step-by-step algorithm.

\section{AN ALGORITHM FOR CONSTRUCTING THE DYNAMIC RISK MEASURES VAR AND CVAR FORECAST BASED ON THE METHOD QLGARCH - METALOG}

1. Building a variance model to get estimates. The model $\operatorname{LGARCH}(p, q)$

(1) is written as $\operatorname{ARCH}(\infty): \sigma_{t}=\alpha_{0}+\sum_{j=1}^{\infty} \alpha_{j}\left|u_{t-j}\right|$, where the coefficients $\alpha_{j}$ 
satisfy summability conditions implied by the regularity conditions [6]. Due to the assumption of regularity, the coefficients decrease geometrically, therefore, the model can be reduced to ARCH $(m)$. The appropriate lag for reducted $\mathrm{ARCH}$ model is chosen on the base of significant values of ACF and PACF for squared values of returns (values that is more than confidence bounds). Estimates of $\alpha_{j}$ can be obtained in various ways. QMLE is used in this work. The fitted model is used to obtain estimates $\hat{\sigma}_{t}, \ldots, \hat{\sigma}_{t-p}$ :

$$
\hat{\sigma}_{t-i}=\hat{\alpha}_{0}+\sum_{j=1}^{m} \hat{\alpha}_{j}\left|u_{t-j-i}\right|, \quad i=\overline{0, p} .
$$

2. Building a set of quantiles predictive estimates. To obtain estimates of the $\tau$-quantile for $u_{t}$, the QLGARCH model (9) is used. The orders of the model $p, q$ can be estimated using Akaike Inform Criteria (AIC) and Hannan-Quinn Inform Criteria (HQIC). It is also possible to use Bayes Inform Criteria (BIC) and Shibata Inform Criteria (SIC). To estimate the vector of parameters $\theta(\tau)^{\mathrm{T}}$, the minimization problem is solved using the quantile regression estimation in the form (see [8]):

$$
\min _{\theta} \sum_{t} \rho_{\tau}\left(u_{t}-\theta\left((\tau)^{\mathrm{T}} \hat{z}_{t}\right),\right.
$$

where $\rho_{\tau}(u)=u(\tau-I(u<0))$ is a check function, $\hat{z}_{t}=\left(1, \hat{\sigma}_{t-1}, \ldots, \hat{\sigma}_{t-p},\left|u_{t-1}\right|, \ldots\right.$ ..., $\left.\left|u_{t-q}\right|\right|^{\mathrm{T}}$ taking into account that the estimates $\hat{\sigma}_{t-1}, \ldots, \hat{\sigma}_{t-p}$ were obtained at step 1 (10). The solution of the unconstrained minimization problem (11) makes it possible to estimate the $\tau$-quantile for $u_{t}$ in the form:

$$
\hat{Q}_{u_{t}}\left(\tau \mid \Phi_{t-1}\right)=\hat{\theta}(\tau)^{\mathrm{T}} \hat{\boldsymbol{z}}_{t}
$$

At this step, a grid of $\tau_{i}$-quantiles, $i=\overline{1, N}$, is constructed and the problem (11) is solved $N$ times. For every quantile regression with $\tau_{i}, i=\overline{1, N}$ the quantile estimates are $\hat{Q}_{u_{t}}\left(\tau_{i}\right)=\hat{\theta}_{t}\left(\tau_{i}\right)^{T} \hat{\boldsymbol{z}}_{t}, i=\overline{1, N}$. In this case, the predicted values of the conditional quantiles are calculated by extrapolation $\hat{Q}_{u_{t+1}}\left(\tau_{i}\right)=\hat{\theta}\left(\tau_{i}\right)^{\mathrm{T}} \hat{\boldsymbol{z}}_{t+1}$, where $\hat{z}_{t+1}=\left(1, \hat{\sigma}_{t}, \ldots, \hat{\sigma}_{t-p+1},\left|u_{t}\right|, \ldots, \mid u_{t-q+1}\right)^{\mathrm{T}}$, and $\hat{\sigma}_{t-i}$, $i=\overline{0, p-1}$ are obtained at the first step of algorithm (10).

3. Risk measures forecasting. The predictive quantiles $\hat{Q}_{u_{t+1}}\left(\tau_{1}\right), \ldots$ $\ldots, \hat{Q}_{u_{t+1}}\left(\tau_{N}\right)$ (from previous step) are fitted using the metalog distribution. Estimates of the metalog distribution parameters $\hat{\boldsymbol{a}}=\left(\hat{a}_{1}, \hat{a}_{2}, \ldots, \hat{a}_{n}\right)^{\mathrm{T}}$ are found in accordance with (6), where $\boldsymbol{X}=\left(\hat{Q}_{u_{t+1}}\left(\tau_{1}\right), \ldots, \hat{Q}_{u_{t+1}}\left(\tau_{N}\right)\right)^{\mathrm{T}}, \boldsymbol{\alpha}=\left(\tau_{1}, \tau_{2}, \ldots, \tau_{N}\right)^{\mathrm{T}}$. Specifying the quantile function $M_{n}(\widetilde{\alpha}, \hat{\boldsymbol{a}})$ for a given level $\widetilde{\alpha}$ allows the use of analytical expressions (7), (8) to find the predicted values $\operatorname{VaR}_{\widetilde{\alpha}}^{t+1}$ and $C V a R_{\widetilde{\alpha}}^{t+1}$. 


\section{EXPERIMENT, RESULTS AND DISCUSSIONS}

Proposed algorithm was applied for dynamic risk measures $V a R_{0,1}, C V a R_{0,1}$ forecasting for the time series of daily $\log$ returns of the Dow Jones Industrial Average index (the DJI time series). The sample length was 3500 values from $2007 / 02 / 16$ to $2021 / 01 / 11$. The forecast model was based on 1500 historical values and was extrapolated one value forward. After that, the modeling window was one step shifted, and the model was rebuilt. The procedure was repeated 2000 times (Rolling Forecast Method). The obtained one-step forecasts were compared with real values for the corresponding period of time. To obtain variance estimates (10), the model $\operatorname{ARCH}(30)$ was built. Based on the historical values of the time series and the estimated variance values, quantile $\operatorname{LGARCH}(p, q)$ models were built for different levels of quantiles. The orders of the models were found using the AIC and HQIC criteria: $p=3, q=3$. For more detailed description of the left tail of the distribution, the non uniform grid of quantiles was used: $\tau_{i}=i h$, $h=0,01$ for $i=\overline{1,20}$, and $h=0,05$ for $i=\overline{5,19}$. Estimates of the parameters were obtained using QMLE. The estimated models were used to generate one-step quantile predictions. The predicted quantile values were used to estimate the metalog distribution. Using (6), the estimates for the coefficients of the metalog distributions for $n=4,5,6,7$ were obtained. Risk measures estimates were calculated using formulas (7) and (8). The results were obtained using $R$ packages rugarch [15] and quantreg [16].

The results of dynamic $V a R$ and $C V a R$ risk measures forecasting using the QLGARCH - Metalog (rq met) method are shown in Fig. 1 along with the historical values (the first 1500) and the real values (1501-3500) of the DJI time series. As can be seen from the graph, the obtained forecast estimates describe the dynamic behavior of the time series quite well.

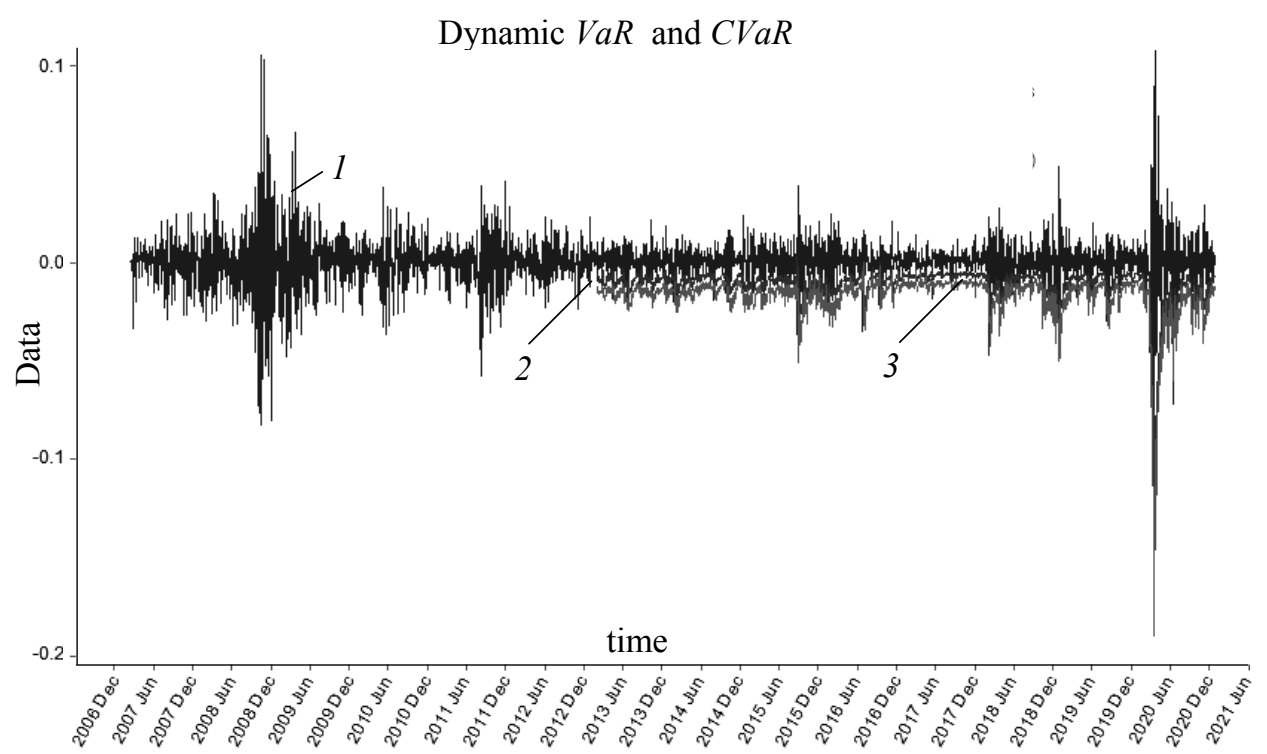

Fig. 1. Historical data of the time series of daily log return of the DJI index $(1$ - TS returns) from $2007 / 02 / 16$ to $2021 / 01 / 11$ and the forecast values for $\operatorname{VaR}_{0.1}^{t+1}(2-\operatorname{VaR}(0,1))$ and $C V a R_{0,1}^{t+1}(3-C \operatorname{VaR}(0,1))$ obtained by the QLGARCH - Metalog method $(n=5)$ for the period 2013/02/01 - 2021/01/11 
Historical data and the forecast values of dynamic risk measures over a short period of time is shown in Fig. 2 for more convenient visual analysis.

Dynamic $V a R$ and $C V a R$

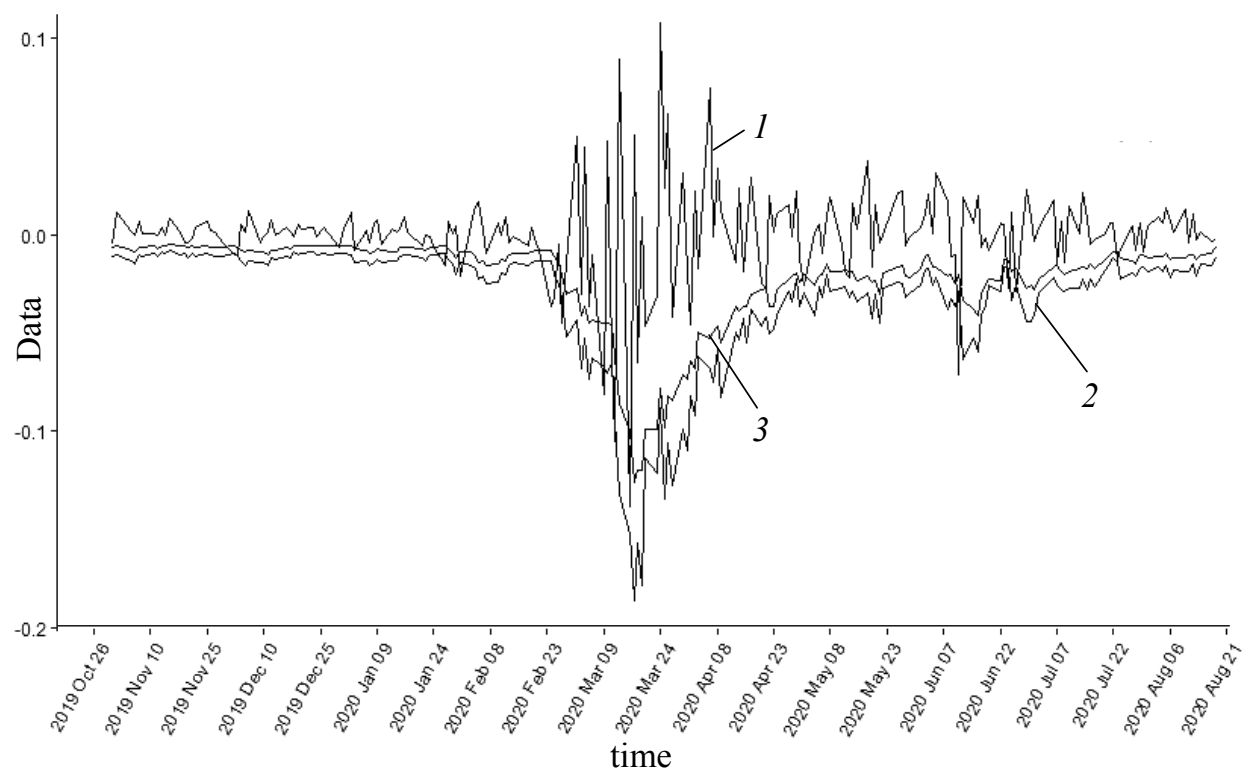

Fig. 2. Historical data of the time series of daily log return of the DJI index ( $1-$ TS returns) and the forecast values for for $\operatorname{VaR}_{0.1}^{t+1}(2-\operatorname{VaR}(0,1))$ and $C V a R_{0,1}^{t+1}$ $(3-C \operatorname{VaR}(0,1))$ obtained by the QLGARCH - Metalog method $(n=5)$ for the period 2019/10/31-2020/08/18

For a comparative analysis of the effectiveness of the proposed method, a forecast of dynamic risk measures for a given time series was built with standard approach on the basis of a heteroscedastic model (3). To estimate the variance, the LGARCH $(3,3)$ model was considered. The AIC and HQIC criteria were used to determine the orders of the model. The QMLE was used to estimate the model coefficients. To determine the risk measures for the residuals of the LGARCH $(3,3)$ model, the following methods were used: the Historical simulation method (4) (hist method), explicit formulas (5) under the assumption that the model residuals have the local scale t-distribution (tLS method), explicit formulas (7), (8) based on Quantile Metalog Method for $n=4,5,6,7$ (metal method).

The analysis of the constructed forecast estimates was carried out using the backtesting procedure. The following tests were used in the work:

- for VaR estimates: the Kupiec test (LRuc), Christoffersen's independence test (LRind), PoE statistics [17];

- for CVaR estimates: two tests proposed in [18]: one-sided simple conditional calibration test (scc_1) and two-sided simple conditional calibration test (scc_2); three regression based backtests proposed in [19]: the auxiliary ESR backtest (Aux), the strict ESR backtest (Str), the intercept ESR backtest (Int).

The $p$-values of these tests are shown in Table 1. Table 2 shows the PoE statistic values for the forecast estimates of dynamic risk measure $\mathrm{VaR}$. 
Table 1. The results of the qualitative analysis of the forecast estimates of dynamic risk measures $V a R$ and $C V a R$ for DJI time series

\begin{tabular}{|c|c|c|c|c|c|c|c|}
\hline \multirow{2}{*}{ Method } & \multicolumn{7}{|c|}{ Risk meashure } \\
\cline { 2 - 8 } & \multicolumn{2}{|c|}{ VaR } & \multicolumn{5}{c|}{ CVaR } \\
\cline { 2 - 8 } & LRuc & LRind & scc_1 & scc_2 & Aux & Str & Int \\
\hline hist & 0,0677 & 0,0091 & 0,0866 & 0,0076 & 0,6453 & 0,6191 & 0,5824 \\
\hline tLS & 0,4582 & 0,3359 & 0,0657 & 0,1136 & 0,5364 & 0,5286 & 0,4710 \\
\hline metal, $n=4$ & 0,1497 & 0,0802 & 0,2301 & 0,0625 & 0,6980 & 0,7289 & 0,6267 \\
\hline metal, $n=5$ & 0,1726 & 0,1497 & 0,2411 & 0,0630 & 0,6883 & 0,7338 & 0,6461 \\
\hline metal, $n=6$ & 0,0945 & 0,0393 & 0,1251 & 0,0115 & 0,5707 & 0,6047 & 0,5355 \\
\hline metal, $n=7$ & 0,0945 & 0,0474 & 0,1245 & 0,0098 & 0,5261 & 0,5521 & 0,5180 \\
\hline rq_met, $n=4$ & 0,4983 & 0,7643 & 0,1572 & 0,0869 & 0,8454 & 0,8914 & 0,8072 \\
\hline rq_met, $n=5$ & 0,8810 & 0,5796 & 0,2741 & 0,1808 & 0,8842 & 0,9164 & 0,8475 \\
\hline rq_met, $n=6$ & 0,4272 & 0,4072 & 0,1863 & 0,1082 & 0,8566 & 0,8931 & 0,8121 \\
\hline rq_met, $n=7$ & 0,5476 & 0,3655 & 0,2688 & 0,1757 & 0,8671 & 0,8940 & 0,8450 \\
\hline
\end{tabular}

Table 2. PoE statistic values for the forecast estimates of dynamic risk measure VaR for DJI time series

\begin{tabular}{|c|c|c|c|c|c|c|c|c|c|c|}
\hline \multirow{2}{*}{ Method } & \multirow{2}{*}{ hist } & \multirow{2}{*}{ tLS } & \multicolumn{4}{|c|}{ metal } & \multicolumn{4}{|c|}{ rq_met } \\
\cline { 4 - 10 } & & & $n=4$ & $n=5$ & $n=6$ & $n=7$ & $n=4$ & $n=5$ & $n=6$ & $n=7$ \\
\hline $\mathrm{PoE}$ & 0,0879 & 0,1051 & 0,09045 & 0,09095 & 0,0889 & 0,0889 & 0,0954 & 0,0989 & 0,0944 & 0,0959 \\
\hline
\end{tabular}

As follows from Table 1, the worst estimates were obtained using the historical simulation method (hist). In particular, as a result of applying the Christoffersen's independence test (LRind) for $V a R$ and the two-sided simple conditional calibration test ( $\operatorname{scc} 2$ ) for $C V a R$, hypotheses with a significance level of 0,05 were rejected. This indicates the inapplicability of the historical simulation method for predicting the values of the DJI time series. At the same time, all tests showed consistently good quality of forecasts obtained by the QLGARCH - Metalog method (rq met) and maximum $p$-value statistics compared to other methods (tLS and metal).

In the article the metalog distribution with the different number of parameters $(n=4,5,6,7)$ was considered (see Table 1). An increase in the number of parameters potentially increases the accuracy of the estimates, but can lead to the problem of overfitting. As a result of the backtesting for forecasted dynamic risk measures $\mathrm{VaR}$ and $\mathrm{CVaR}$ obtained with the Quantile Metalog Method (metal), the choose of large $n$ probably leads to overfitting. The estimates of $\operatorname{VaR}$ and $C V a R$ obtained using the metalog distribution for $n=4$ and $n=5$ are consistently better than the estimates obtained using the same sample for $n=6$ and $n=7$. At the same time, the QLGARCH - Metalog (rq met) method shows less dependence on the number of parameters of the metalog distribution. The results of the qualitative analysis for $V a R$ and $C V a R$ forecasts obtained by this method are relatively uniform for all $n$. Although it should be noted that according to the results of all tests, the highest quality forecasts for risk measures were obtained at $n=5$. The best results of $V a R$ forecasting (see Table 2) according to PoE statistics is obtained also by rq met method for $n=5$ (has the least deviation from the target value of 0,1 ). 
The paper proposes a method that is a natural continuation of existing research and methods devoted to dynamic risk models developing. It combines parametric and nonparametric statistical approaches to time series modeling. Practical application of the method shows its effectiveness in the case of risk modeling for highly volatile financial time series. The simplicity of the method and its background make it possible to recommend it for using in various fields. However, the determination of the restrictions on applicability of this method, as well as the automation of the procedure for estimation of its parameters, requires further mathematical research, in particular, the construction of asymptotic estimates of the convergence of the model.

\section{CONCLUSIONS}

The paper considers the problem of dynamic $V a R$ and $C V a R$ risk measures modeling and forecasting for financial time series. Since the $V a R$ measure is a conditional quantile of the distribution function of a given level, and CVaR for continuous distributions can be specified as the average of the quantile function it is proposed to use QLGARCH as a model for risk measures forecasting. The advantage of using of this model is the ability to estimate and predict not the full distribution, but the values of the quantiles of the required levels. Since the risk measures are determined for the tail part of the distribution, an non uniform grid is used in the work, which makes it possible to detail the quantiles with a low level. To smooth point values, it is proposed to fit a set of quantiles with metalog distribution. This approach is also convenient due to the presence of explicit analytical expressions $\operatorname{VaR}$ and $C V a R$ for the metalog distribution. The proposed method for dynamic $\mathrm{VaR}$ and $\mathrm{CVaR}$ risk measures forecasting is formulated in the form of a step-by-step algorithm.

The proposed methodology was tested on the time series of daily log return of the Dow Jones Industrial Average (DJI) index for the period from 2007-02-16 to 2021-01-11. Using the formulated algorithm, a set of one-step forecasts of risk measures was obtained. An analysis of the quality of the forecasts was carried out using various standard backtesting techniques on real data. The results were compared with the forecasts obtained by standard methods that are based on the LGARCH model and various assumptions about distribution of the residuals. The carried out qualitative analysis of the obtained predicted values showed the effectiveness of using the method proposed in this work and its advantage in comparison with standard methods.

The results of the work can be directly applied in dynamic risk modeling for highly volatile time series, in particular, financial time series, and also can serve as the basis for the development of new methods and algorithms for random processes prediction.

\section{REFERENCES}

1. McNeil R. Frey and P. Embrechts, Quantitative Risk Management: Concepts, Techniques, and Tools. New Jersey, USA: Princeton University Press, 2005.

2. N. Pankratova and N. Zrazhevska, "Method of dynamic var and cvar risk measures forecasting for long range dependent time series on the base of the heteroscedastic model", Intelligent Control and Automation, vol.8, pp. 126-138, Jan. 2017. Available: https://doi.org/10.4236/ica.2017.82010 
3. H. Badaye and J. Narsoo, "Forecasting multivariate var and es using mc-garchcopula model", The Journal of Risk Finance, vol. 21, no. 5, pp. 493-516, 2020. Available: https://doi.org/10.1108/JRF-06-2019-0114

4. S. Paul and P. Sharma, "Quantile forecasts using the realized garch-evt approach", Studies in Economics and Finance, vol. 35, no. 4, pp. 481-504, Oct. 2018. Available: https://doi.org/10.1108/SEF-09-2016-0236

5. Z. Xiao and R. Koenker, "Conditional quantile estimation for generalized autoregressive conditional heteroscedasticity models", Journal of the American Statistical Association, vol.104, pp. 1696-1712, Dec. 2009. Available: https://doi.org/10.1198/ jasa. 2009.tm09170

6. R. Koenker, V. Chernozhukov, X. He, and L. Peng, Handbook of Quantile Regression [1st ed.]. Boca Raton, USA: CRC Press, 2017. Available: https://doi.org/10.1201/ 9781315120256

7. Y. Zheng, Z. Qianqian, G. Li, and Z. Xiao, "Hybrid quantile regression estimation for time series models with conditional heteroscedasticity", Journal of the Royal Statistical Society: Series B (Statistical Methodology), vol. 80, issue 5, pp. 975-993, Nov. 2018. Available: https://doi.org/10.1111/rssb.12277

8. G. Wang, K. Zhu, G. Li, and W.K. Li, "Hybrid quantile estimation for asymmetric power garch models", Journal of Econometrics, Aug. 2020. Available: https: //www.sciencedirect.com/science/article/abs/pii/S0304407620302220, Accessed on: 6 August 2020. Available: https://doi.org/10.1016/j.jeconom. 2020.05.005.

9. T. Keelin, "The metalog distributions", Decision Analysis, vol. 13, issue 4, pp. 243-277, Dec. 2016. Available: https://doi.org/10.1287/deca.2016.0338

10. J. Wang, M. Neil, and N. Fenton, "A bayesian network approach for cybersecurity risk assessment implementing and extending the fair model", Computers \& Security, vol. 89, 2020. Available: https://doi.org/10.1016/j.cose.2019.101659

11. P. Dion, N. Galbraith, and E. Sirag, "Using Expert Elicitation to Build Long-Term Projection Assumptions", in Developments in Demographic Forecasting. The Springer Series on Demographic Methods and Population Analysis, vol. 49, Springer, Cham, 2020, pp. 43-62. Available: https://doi.org/10.1007/978-3-030-42472-5_3

12. R. Bratvold, E. Mohus, D. Petutschnig, and J. Bickel, "Optimistic and Overconfident-Over and Over Again”, SPE Reservoir Evaluation and Engineering, vol. 23, May 2020. Available: https://doi.org/10.2118/195914-PA

13. V. Zrazhevska and G. Zrazhevsky, "Generalized approach for estimating and forecasting of dynamical var and cvar based on metalog distribution", Lecture Notes in Computational Intelligence and Decision Making, in Babichev S., Lytvynenko V., Wójcik W., Vyshemyrskaya S. (eds), ISDMCI 2020. Advances in Intelligent Systems and Computing, vol. 1246. Springer, Cham. Available: https://doi.org/10.1007/9783-030-54215-3 15

14. N.G. Zrazhevskaja and A.G. Zrazhevskij, "Classification of methods for risk measures var and cvar calculation and estimation", System research and information technologies, vol. 3, pp. 118-125, Sep. 2016. Available: https://doi.org/10.20535/ SRIT. 2308-8893.2016.3.11

15. A. Ghalanos, Introduction to the rugarch package (Version 1.4-3). Available: https://cran.r-project.org/web/packages/rugarch/vignettes/Introduction_to_the_rugarch_ package.pdf [July 15, 2020]

16. R. Koenker, Quantile regression in R: a vignette. Available: https://cran.r-project. $\mathrm{org} / \mathrm{web} /$ packages/quantreg/vignettes/rq.pdf [June 28, 2019].

17. G. Zrazhevsky, A. Golodnikov, S. Uryasev, and A. Zrazhevsky, "Application of buffered probability of exceedance in reliability optimization problems", Cybernetics and Systems Analysis, vol. 56, pp. 1-9, May 2020. Available: https://doi.org/10. 1007s10559.020.00263.4

18. N. Nolde and J.F. Ziegel, "Elicitability and backtesting: Perspectives for banking regulation", The Annals of Applied Statistics, vol. 11, no. 4, pp. 1833-1874, 2017. Available: https://doi.org/10.1214/17-AOAS1041 
19. S. Bayer and T. Dimitriadis, "Regression-Based Expected Shortfall Backtesting", Journal of Financial Econometrics, September, 2020. Available: https://academic. oup.com/jfec/advance-articlepdf/doi/10.1093/jjfinec/nbaa013/33796824/nbaa013.pdf, Accessed on: 27 April 2020. Available: https://doi.org/10.1093/jjfinec/nbaa013

Received 20.03.2021

\section{INFORMATION ON THE ARTICLE}

Grigoriy M. Zrazhevsky, ORCID: 0000-0001-8475-2469, National Taras Shevchenko University of Kyiv, Ukraine, e-mail: zgrig@univ.kiev.ua

Vira F. Zrazhevska, ORCID: 0000-0001-5117-8093, National Technical University of Ukraine "Igor Sikorsky Kyiv Polytechnic Institute", Ukraine, e-mail: vera.zrazhevska@gmail.com

\section{ПРОГНОЗУВАННЯ ДИНАМІЧНИХ VAR I CVAR HA OCHОВI КВІНТИЛЬНОЇ РЕГРЕСІї 3 ВИКОРИСТАННЯМ МЕТАЛОГ РОЗПОДІЛУ / Г.М. Зражевський, В.Ф. Зражевська}

Анотація. Запропоновано новий метод динамічного прогнозування мір ризику VaR i CVaR (ES). Як основна модель прогнозування для квантилів часових рядів обрано квантильну лінійну модель GARCH. Для побудови прогнозу значення квантилів апроксимуються розподілом металог, що дозволяє використовувати аналітичні формули для оцінювання мір ризику. Методику прогнозування VaR i CVaR сформульовано у вигляді покрокового алгоритму. На першому етапі будується вихідна модель для отримання оцінок дисперсії. Отримані за моделлю значення дисперсії використовуються на другому етапі для знаходження коефіцієнтів моделі QLGARCH шляхом розв'язання задачі мінімізації. На третьому етапі моделі QLGARCH оцінюються на неоднорідній квантильній сітці. Отримані прогнозні значення квантилів використовуються для оцінки параметрів розподілу металог. Розроблений метод застосовується до прогнозування VaR i CVaR для часового ряду логарифмічної дохідності індексу DJI.

Ключові слова: VaR, CVaR, Expected Shortfall, динамічні міри ризику, прогноз, квантильна модель LGARCH, розподіл металог.

ПРОГНОЗИРОВАНИЕ ДИНАМИЧЕСКИХ VAR И CVAR НА ОСНОВЕ КВИНТИЛЬНОЙ РЕГРЕССИИ С ИСПОЛЬЗОВАНИЕМ МЕТАЛОГ РАСПРЕДЕЛЕНИЯ / Г.М. Зражевский, В.Ф. Зражевская

Аннотация. Предложен новый метод динамического прогнозирования мер риска $\mathrm{VaR}$ и CVaR (ES). Квантильная линейная модель GARCH выбрана в качестве основной модели прогнозирования для квантилей временных рядов. Для построения прогноза значения квантилей аппроксимируются распределением металог, что позволяет использовать аналитические формулы для оценки мер риска. Методика прогнозирования $\mathrm{VaR}$ и $\mathrm{CVaR}$ сформулирована в виде пошагового алгоритма. На первом этапе строится исходная модель для получения оценок дисперсии. Полученные по модели значения дисперсии используются на втором этапе для нахождения коэффициентов модели QLGARCH путем решения задачи минимизации. На третьем этапе модели QLGARCH оцениваются на неоднородной квантильной сетке. Полученные прогнозные значения квантилей используются для оценки параметров распределения металог. Разработанный метод применен к прогнозированию VaR и CVaR для временного ряда логарифмической доходности индекса DJI.

Ключевые слова: VaR, CVaR, Expected Shortfall, динамические меры риска, прогно3, квантильная модель LGARCH, распределение металог. 